\title{
Frequencies of BCR-ABL1 fusion transcripts among Sudanese chronic myeloid leukaemia patients
}

\author{
Emad-Aldin I. Osman ${ }^{1}$, Kamal Hamad ${ }^{2}$, Imad M. Fadl Elmula ${ }^{3}$ and Muntaser E. Ibrahim ${ }^{1}$ \\ ${ }^{1}$ Department of Molecular Biology, Institute of Endemic Diseases, University of Khartoum, Khartoum, \\ Sudan. \\ ${ }^{2}$ Faculty of Medicine, University of Khartoum, Khartoum, Sudan. \\ ${ }^{3}$ Faculty of Medical Laboratories sciences, Al-Neelain University, Khartoum, Sudan.
}

\begin{abstract}
The incidence of one or other rearrangement in chronic myeloid leukemia $(C M L)$ patients varies in different reported series. In this study we report the frequencies of BCR-ABL1 fusion transcript variants studied in 43 CML patients from Sudan. The study includes 46 Sudanese patients, three of which negative for the BCR-ABL1 fusion transcript. More than half of 43 positive patients showed b2a2 fusion transcript (53.5\%), while (41.9\%) showed b3a2 transcript and the remaining (4.6\%) coexpression of b3a2/ b2a2 and b3a2/b2a2/e19a2. We detected neither coexpression of p210/p190 nor e1a2 alone. Male patients showed a tendency to express b2a2, while female tende to express b3a2 $(p=0.017)$. Moreover, a single nucleotide polymorphism was detected in BCR exon 13 in one out of four patients and this patient showed only b2a2 expression. In conclusion, we observed a significant correlation between sex and type of BCR-ABL1 transcript, an observation that deserves further investigation.
\end{abstract}

Key words: BCR-ABL, chronic myeloid leukemia, Ph chromosome, Sudanese, RT-PCR.

Received: August 20, 2009; Accepted: November 17, 2009.

The Philadelphia $(\mathrm{Ph})$ chromosome was the first chromosomal abnormality to be associated with a specific malignant disease in humans, namely chronic myeloid leukemia (CML). This is a shortened chromosome 22 resulting from reciprocal translocation, $\mathrm{t}(9 ; 22)(\mathrm{q} 34 ; \mathrm{q} 11)$, between the long arms of chromosomes 9 and 22. This translocation results in the formation of two hybrid genes, BCR-ABL1 on the $\mathrm{Ph}$ chromosome and ABL1-BCR on $9 \mathrm{q}+$ (Melo, 1996). A Ph chromosome is the hallmark of CML and is found in up to $95 \%$ of the patients. It is also found in $5 \%$ of children and in 15 to $30 \%$ of adults with acute lymphoid leukemia, and in $2 \%$ of patients with newly diagnosed acute myeloblastic leukemia (Kurzrock et al., 1988).

In most CML patients, the break in chromosome 22 is restricted to an area of 5.8-kb termed M-bcr. M-bcr consists of five exons termed M-bcr exons b1-b5. These exons are actually located within the central region of the BCR gene and are equivalent to exons 12-16 (e12- e16) of this gene. Most breaks occur immediately downstream of exon 2 or 3 of the $\mathrm{M}$-bcr region and result in $\mathrm{b} 2 \mathrm{a} 2$ or $\mathrm{b} 3 \mathrm{a} 2$ fusion transcripts (Groffen et al., 1984). A very small proportion of Phpositive CML patients display a larger BCR-ABL1 fusion transcript that results from a fusion between BCR exon 19

Send correspondence to Muntaser E. Ibrahim. Medical Campus, University of Khartoum, Qasser Street Khartoum, P.O. Box 102, Sudan. E-mail: mibrahim@iend.org. (originally named c3) and ABL exon 2. This is caused by breakpoints in the $\mu$-breakpoint cluster region ( $\mu$-bcr) between BCR exons 19 and 20 (van Dongen et al., 1999). This e19a2 (c3/a2) junction yields a transcript that contains an additional BCR sequence of $540 \mathrm{bp}$ and encodes for a chimeric protein carrying 180 additional amino acids, as compared with that found in typical CML (Pane et al., 1996).

In 60 to $80 \%$ of all patients with Ph-positive ALL, the breakpoint occurs in the first intron of the BCR gene, in a region referred to as the minor breakpoint cluster region (m-bcr), thereby producing the shorter isotype p190 BCRABL1 from the ela2 type mRNA (Deininger et al., 2000). Although the e1a2 type of transcript has been mainly associated with ALL, sporadic cases of CML expressing only this type of transcript have also been reported (Selleri et al., 1990).

The majority of CML patients have transcripts with the $\mathrm{b} 3 \mathrm{a} 2(55 \%)$ or b $2 \mathrm{a} 2(40 \%)$ junctions. In $5 \%$ of the cases, both $\mathrm{b} 3 \mathrm{a} 2$ and $\mathrm{b} 2 \mathrm{a} 2$ transcripts can be formed as a result of alternative splicing (Melo, 1996).

This study was carried out to determine the frequency of expression of BCR-ABL1 fusion transcript variants in Sudanese CML patients by using RT-PCR, and was partly motivated by the introduction of imatinib mesylate, whose administration is currently based on the molecular diagnosis of BCR-ABL1 fusion genes. 
Blood samples from 46 patients with preliminary diagnosis of CML for the period 2004 to 2008, were obtained for confirmation by molecular studies. Preliminary diagnosis was carried out according to clinical presentation and morphological criteria of blood and bone marrow. Written informed consent was obtained from all the patients or family members.

Venous blood $(5 \mathrm{~mL})$ in EDTA tubes was collected from the CML patients. Buffy coat was isolated and washed in red cells lysis buffer. Total RNA was extracted from about $10^{6}$ white cells by Trizol (Invitrogen). RNA integrity was determined by gel electrophoresis prior to reverse transcription.

For cDNA synthesis, the concentration of RNA was first measured spectrophotometrically, and then the cDNA was synthesized using M-MuLV Reverse Transcriptase and other reaction components (Fermentas). $2 \mu \mathrm{g}$ of RNA were reverse transcribed with 200 units of M-MuLV RT in a reaction mix consisting of $1 \mathrm{x}$ RT buffer $(50 \mathrm{mM}$ Tris- $\mathrm{HCl}$ , $50 \mathrm{mM} \mathrm{KCl}, 4 \mathrm{mM} \mathrm{MgCl} 2,10 \mathrm{mM}$ DTT), $0.5 \mu \mathrm{g}$ of oligo(dT) $)_{18}, 20 \mathrm{mM}$ dNTP and 20 units RNase inhibitor, in a final volume of $20 \mu \mathrm{L}$. Reaction conditions were $70^{\circ} \mathrm{C}$ for $5 \mathrm{~min}, 37^{\circ} \mathrm{C}$ for $5 \mathrm{~min}, 42^{\circ} \mathrm{C}$ for $1 \mathrm{~h}$ and $70^{\circ} \mathrm{C}$ for $10 \mathrm{~min}$.

BCR-ABL1 transcripts were detected by PCR, using allele-specific primers for p210 and p190 primer sequences, as already described (van Dongen et al., 1999). The (A2) primer ' 5 TTC AGC GGC CAG TAG CAT CTG ACT T 3' was also used for ABL1 as forward together with a reverse primer. PCR was carried out in a total volume of $23 \mu \mathrm{L}$ of a reaction mixture containing $2.5 \mu \mathrm{L}$ of $10 \mathrm{X}$ PCR buffer $(10 \mathrm{mM}$ Tris-HCl $\mathrm{pH} 8.3,50 \mathrm{mM} \mathrm{KCl}), 2.5 \mu \mathrm{L}$ of $25 \mathrm{mM} \mathrm{MgCl}_{2}, 1 \mu \mathrm{L}$ of $10 \mathrm{mM}$ dNTPs, $2 \mu \mathrm{L}$ of $10 \mu \mathrm{M}$ of forward and reverse primers, $14 \mu \mathrm{L}$ of $\mathrm{H}_{2} \mathrm{O}$ and $1 \mu \mathrm{L}$ of $1 \mathrm{U} / \mu \mathrm{L}$ Taq DNA polymerase. A touchdown program was employed, under the following conditions: an initial denaturation step at $95^{\circ} \mathrm{C}$ for $3 \mathrm{~min}$., then followed by 14 cycles of denaturing at $94{ }^{\circ} \mathrm{C}$ for $20 \mathrm{~s}$, primer annealing at $64{ }^{\circ} \mathrm{C}$ and a decrease $0.5^{\circ} \mathrm{C}$ per cycle for $30 \mathrm{~s}$, extension at $72{ }^{\circ} \mathrm{C}$ for $45 \mathrm{~s}$, then 35 cycle as following: denaturing at $94^{\circ} \mathrm{C}$ for $20 \mathrm{~s}$, primer annealing at $58^{\circ} \mathrm{C}$ for $30 \mathrm{~s}$, extension at $72{ }^{\circ} \mathrm{C}$ for $45 \mathrm{~s}$ and a final extension step at $72{ }^{\circ} \mathrm{C}$ for $5 \mathrm{~min}$. PCR was done using separate reactions for each pair of primers. The PCR products were visualized directly on ethidium bromide-stained $2 \%$ agarose gel. ABL1 gene was used as internal control. Bands of $417 \mathrm{bp}, 342 \mathrm{bp}, 957 \mathrm{bp}$ and 226 bp were observed for $\mathrm{b} 3 \mathrm{a} 2, \mathrm{~b} 2 \mathrm{a} 2$, e $19 \mathrm{a} 2$ and normal ABL1, respectively.

The PCR products were sent for commercial sequencing at Macrogen Company (South Korea).

The Chi square method was applied for comparing obtained BCR-ABL1 variants of the CML patients by gender.

Of the 46 patients studied, 43 were positive for one or more of the BCR-ABL1 rearrangements. The b2a2 tran- script was detected in $23(53.5 \%)$ of the CML patients, b3a2 in $18(41.9 \%)$, both b2a2 and b3a2 in one (2.3\%) patient, and b2a2, b3a2 with e19a2 also in one (2.3\%) patient. The e1a2 transcript was not detected. Of the $43 \mathrm{CML}$ patients, 20 were males, 15 expressing b2a2, and 23 females, 13 of which expressing b3a2, and two females showed co-expression. We found a correlation between the obtained BCR-ABL1 variants and the sex type of the CML patients $(p=0.017)$. Table 1 shows the BCR-ABL1 transcript types and the patients' gender.

The distribution of transcript type in CML has been studied in European and some other populations (Eisenberg et al., 1988; Lee et al., 1989) with frequencies for b2a2 and b3a2 transcripts being roughly of the order of $40 \%$ and $55 \%$, and that for co-expression of $\mathrm{b} 3 \mathrm{a} 2$ and $\mathrm{b} 2 \mathrm{a} 2$ representing $5 \%$ of the cases. A study on an Ecuadorian population, however, registered very different frequencies: $5 \%$ for b3a2 and 95\% for b2a2 (Paz-y-Mino et al., 2002). In the present study, a frequency of $53.5 \%$ and $41.9 \%$ for b2a2 and b3a2, respectively, was established, values which are is relatively closer to those from a Mexican population (Arana-Trejo et al., 2002). This difference in frequencies may be due to the genetic background of the populations.

Furthermore, it was found that CML patients at diagnosis also expressed either low e1a2 transcript frequency, besides the usual BCR-ABL1 p210 (Saglio et al., 1996; Van Rhee et al., 1996), or only 5\% (Arana-Trejo et al., 2002), or no co-expression whatsoever (Yaghmaie et al., 2008). In this study we did not detect co-expression of p 210 and p190 in any of the Sudanese patients. This may be due to technique sensitivity, although ethnic differences cannot be disregarded.

We found a significant correlation between sex and transcript type, in which male patients showed a higher tendency of expressing b2a 2 and females a higher tendency for b3a2 ( $p=0.017)$. This is in agreement with a study by Adler et al. (2009), which included 146 paediatric patients with $\mathrm{CML}$ and reported the following proportions for the $\mathrm{b} 2 \mathrm{a} 2$ transcript [34 males (51\%) vs. 21 females (27\%)], and inversely for the b3a2 [17 males (25\%) vs. 36 females $(45 \%)]$. In all these cases, the sex-dependent skewed distribution in BCR-ABL1 transcript types deserves further investigation.

In this study, only two patients (4.6\%) manifested co-expression, one expressed $\mathrm{b} 3 \mathrm{a} 2 / \mathrm{b} 2 \mathrm{a} 2$ and the other

Table 1 - Incidence of BCR-ABL1 transcripts and gender.

\begin{tabular}{lcc}
\hline BCR-ABL re-arrangement & Case (\%) & Gender (male/female) \\
\hline b2a2 & $23(53.5 \%)$ & $15 / 8^{*}$ \\
b3a2 & $18(41.9 \%)$ & $5 / 13^{*}$ \\
b2a2/b3a2 & $1(2.3 \%)$ & $0 / 1$ \\
b2a2/b3a2/e19a2 & $1(2.3 \%)$ & $0 / 1$ \\
\hline
\end{tabular}

${ }^{*} \mathrm{p}=0.017$. 
b3a2/b2a2 with e19a2. Co-expression may arise either from alternative splicing, or the existence of several leukemia cell lines with different BCR-ABL1 transcript expression.

Co-expression of $\mathrm{b} 2 \mathrm{a} 2$ and $\mathrm{b} 3 \mathrm{a} 2$ transcripts has been linked to two polymorphisms, $\mathrm{T}$ to $\mathrm{C}$ at exon 13 and $\mathrm{A}$ to $\mathrm{G}$ at intron 13 (Meissner et al., 1998; Branford et al., 2002). Six PCR products from four patients were sequenced to confirm the products of four $\mathrm{b} 2 \mathrm{a} 2$ and two $\mathrm{b} 3 \mathrm{a} 2$ and one was found to harbor $\mathrm{T}$ to $\mathrm{C}$ at exon 13 and expressed only b2a2 transcript which might indicate that this exonic polymorphism is not obligatory for co-expression, as reported by Mondal et al. (2006). Moreover, this polymorphism has no implication on the primary structure of BCR and BCR-ABL1 proteins. However, since the alteration is located close to the fusion region, it may have a significant influence on the annealing of PCR primers, probes for real time PCR, and antisense oligonucleotides. We intend to study this polymorphism in a larger set of CML samples.

Finally, the difference in size of BCR-ABL1 transcripts is not only a reflection of variation at the sites of breakage/fusion, but is also a result of alternative splicing between BCR and ABL and within BCR itself.

\section{Acknowledgments}

This study was supported in part by a grant from the International Atomic Energy Agency.

\section{References}

Adler R, Viehmann S, Kuhlisch E, Martiniak Y, Rottgers S, Harbott J and Suttorp M (2009) Correlation of BCR/ABL transcript variants with patients' characteristics in childhood chronic myeloid leukaemia. Eur J Haematol 82:112-118.

Arana-Trejo RM, Ruiz Sanchez E, Ignacio-Ibarra G, Baez de la Fuente E, Garces O, Gomez Morales E, Castro Granados M, Ovilla Martinez R, Rubio-Borja ME, Solis Anaya L, et al. (2002) BCR/ABL p210, p190 and p230 fusion genes in 250 Mexican patients with chronic myeloid leukaemia (CML). Clin Lab Haematol 24:145-150.

Branford S, Hughes TP and Rudzki Z (2002) Dual transcription of b2a2 and b3a2 BCR-ABL transcripts in chronic myeloid leukaemia is confined to patients with a linked polymorphism within the BCR gene. Br J Haematol 117:875-877.

Deininger MW, Goldman JM and Melo JV (2000) The molecular biology of chronic myeloid leukemia. Blood 96:3343-3356.

Eisenberg A, Silver R, Soper L, Arlin Z, Coleman M, Bernhardt B and Benn P (1988) The location of breakpoints within the breakpoint cluster region (bcr) of chromosome 22 in chronic myeloid leukemia. Leukemia 2:642-647.

Groffen J, Stephenson JR, Heisterkamp N, de Klein A, Bartram CR and Grosveld G (1984) Philadelphia chromosomal breakpoints are clustered within a limited region, bcr, on chromosome 22. Cell 36:93-99.

Kurzrock R, Gutterman JU and Talpaz M (1988) The molecular genetics of Philadelphia chromosome-positive leukemias. N Engl J Med 319:990-998.
Lee MS, LeMaistre A, Kantarjian HM, Talpaz M, Freireich EJ, Trujillo JM and Stass SA (1989) Detection of two alternative bcr/abl mRNA junctions and minimal residual disease in Philadelphia chromosome positive chronic myelogenous leukemia by polymerase chain reaction. Blood 73:21652170.

Meissner RV, Dias PM, Covas DT, Job F, Leite M and Nardi NB (1998) A polymorphism in exon b2 of the major breakpoint cluster region (M-bcr) identified in chronic myeloid leukaemia patients. Br J Haematol 103:224-226.

Melo JV (1996) The diversity of BCR-ABL fusion proteins and their relationship to leukemia phenotype. Blood 88:23752384.

Mondal BC, Bandyopadhyay A, Majumdar S, Mukhopadhyay A, Chandra S, Chaudhuri U, Chakrabarti P, Bhattacharyya S and Dasgupta UB (2006) Molecular profiling of chronic myeloid leukemia in Eastern India. Am J Hematol 81:845849.

Pane F, Frigeri F, Sindona M, Luciano L, Ferrara F, Cimino R, Meloni G, Saglio G, Salvatore F and Rotoli B (1996) Neutrophilic chronic myeloid leukemia: A distinct disease with a specific molecular marker (BCR/ABL with $\mathrm{C} 3 / \mathrm{A} 2$ junction). Blood 88:2410-2414.

Paz-y-Mino C, Burgo R, Morillo SA, Santos JC, Fiallo BF and Leone PE (2002) BCR-ABL rearrangement frequencies in chronic myeloid leukemia and acute lymphoblastic leukemia in Ecuador, South America. Cancer Genet Cytogenet 132:65-67.

Saglio G, Pane F, Gottardi E, Frigeri F, Buonaiuto MR, Guerrasio A, De Micheli D, Parziale A, Fornaci MN, Martinelli G, et al. (1996) Consistent amounts of acute leukemia-associated P190 bcr/abl transcripts are expressed by chronic myelogenous leukemia patients at diagnosis. Blood 87:1075-1080.

Selleri L, von Linderen M, Hermans A, Meijer D, Torelli G and Grosveld G (1990) Chronic myeloid leukemia may be associated with several bcr/abl transcripts including the acute lymphoid leukemia type $7 \mathrm{~kb}$ transcript. Blood 75:1146-1153.

van Dongen JJ, Macintyre EA, Gabert JA, Saglio G, Gottardi E, Rambaldi A, Dotti G, Griesinger F, Parreira A, Gameiro P, et al. (1999) Standardized RT-PCR analysis of fusion gene transcripts from chromosome aberrations in acute leukemia for detection of minimal residual disease. Report of the BIOMED-1 concerted action: Investigation of minimal residual disease in acute leukemia. Leukemia 13:1901-1928.

Van Rhee F, Hochhaus A, Lin F, Melo JV, Goldman JM and Cross NC (1996) p190 BCR/ABL mRNA is expressed at low levels in p210- positive chronic myeloid and acute lymphoblastic leukemias. Blood 87:5213-5217.

Yaghmaie M, Ghaffari SH, Ghavamzadeh A, Alimoghaddam K, Jahani M, Mousavi SA, Irvani M, Bahar B and Bibordi I (2008) Frequency of BCR-ABL Fusion transcripts in Iranian patients with Chronic Myeloid Leukemia. Arch Iran Med 11:247-251.

Associate Editor: Emmanuel Dias Neto

License information: This is an open-access article distributed under the terms of the Creative Commons Attribution License, which permits unrestricted use, distribution, and reproduction in any medium, provided the original work is properly cited. 